\title{
PYELOGENIC DIVERTICULUM OR CALYCEAL DIVERTICULUM
}

Arvinder Singh ${ }^{1}$, Gian S Shergill2, Harbhajan Kaur³, Manjeet Kaur ${ }^{4}$

HOW TO CITE THIS ARTICLE:

Arvinder Singh, Gian S Shergill, Harbhajan Kaur, Manjeet Kaur. "Pyelogenic diverticulum or calyceal diverticulum". Journal of Evolution of Medical and Dental Sciences 2013; Vol2, Issue 37, September 16; Page: 7061-7065.

The term pyelogenic diverticulum, or calyceal diverticulum is defined as a cystic cavity filled with urine within the renal parenchyma. The cyst or diverticulum is lined by transitional epithelium, surrounded by muscularis mucosa. It may be communicating with the collecting system via a narrow isthmus or infundibulum. The incidence of calyceal diverticula is about 2.1-4.5 per 1000 intravenous urographic examinations[1].There are two types are of calyceal diverticulum - one is related to a minor calyx and usually located in the upper pole, while the other is connected with the pelvis or a major calyx in the central portion of the kidney [1]. Mobile calculi and milk of calcium are characteristic findings in PCD $[2,3]$.

KEYWORDS: Calyceal Cyst, Sonography, CT scan.

CASE REPORT: A 23 years old female presented for sonography with dull pain in left lion region. There was no history of fever or urinary tract infection. Her vitals were normal with normal hematocrit. Urine examination does not show any RBCs or polymorphs. The color of urine was clear.

Sonographic examination of left kidney showed a well-defined oblong cystic lesion measuring about $11.7 \times 5.5 \mathrm{~cm}$ in size projecting from the sinus with significantly thick walls. This lesion showed multiple well defined echogenic areas without posterior acousting shadowing in it. Coarse level internal echoes were also seen in it suggestive of 'milk of lime' appearance. Two calculi were seen impacted at its neck near the mid sinus region. Rest of the left renal components were normal [Figure.1a-b].

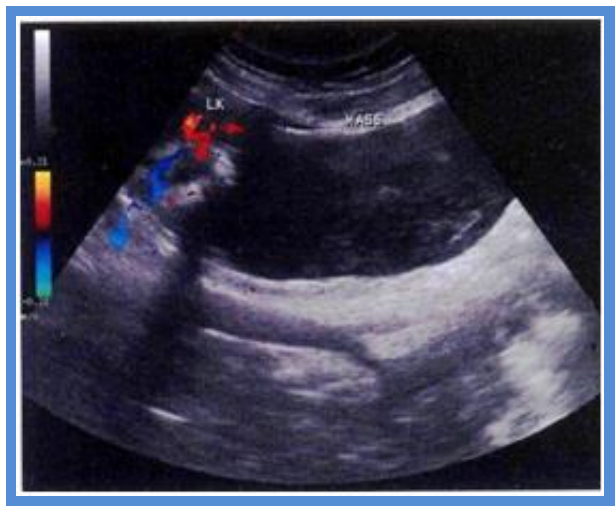

Figure. 1(a) Color Doppler Sonography left kidney showing a large cystic lesion with coarse level internal echogenic sediments suggestive of intracystic milk of calcium with a calculus impacted at its neck.

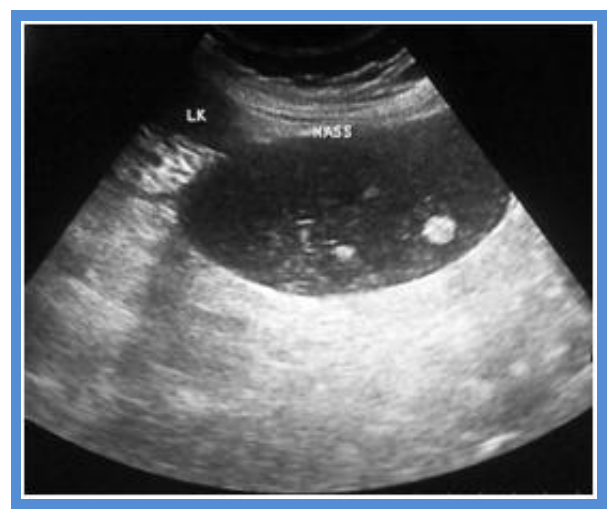

1(b) B-scan of left kidney showing an echogenic round area with milk of calcium inside the renal cyst.

Journal of Evolution of Medical and Dental Sciences/ Volume 2/ Issue 37/ September 16, 2013 


\section{CASE REPORT}

Subsequently, contrast enhanced CT scan of both kidneys was done. A large well defined pyriform shaped cystic mass was seen arising from the left renal sinus. It measured about $11.7 \times 5.5 \mathrm{~cm}$ in size with about two calculi impacted at its neck. No internal septa or any solid components were noted. Delayed scans showed no contrast inside this lesion. The parenchyma of left kidney showed normal enhancement and attenuation [Figure.2, 3].

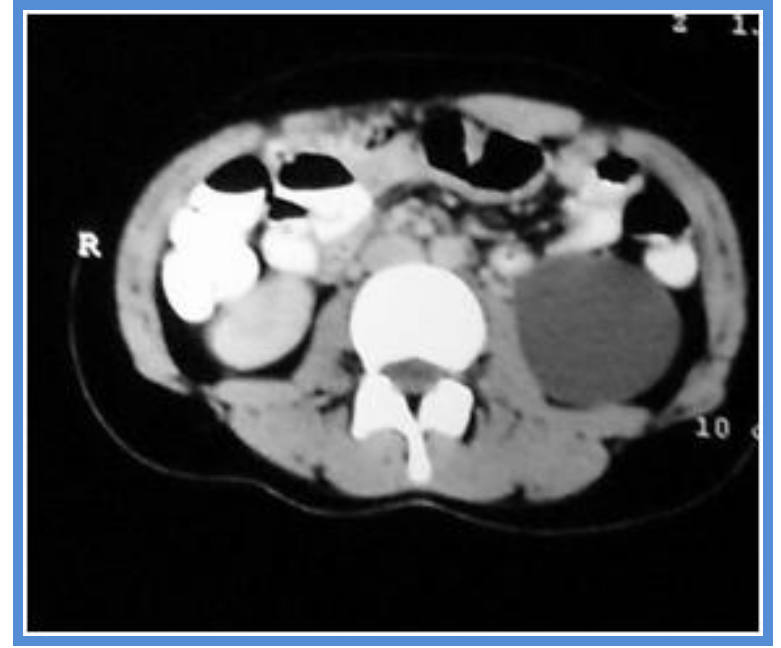

Figure. 2(a) Axial CT Scan image showing a well defined cystic lesion in relation to left renal sinus

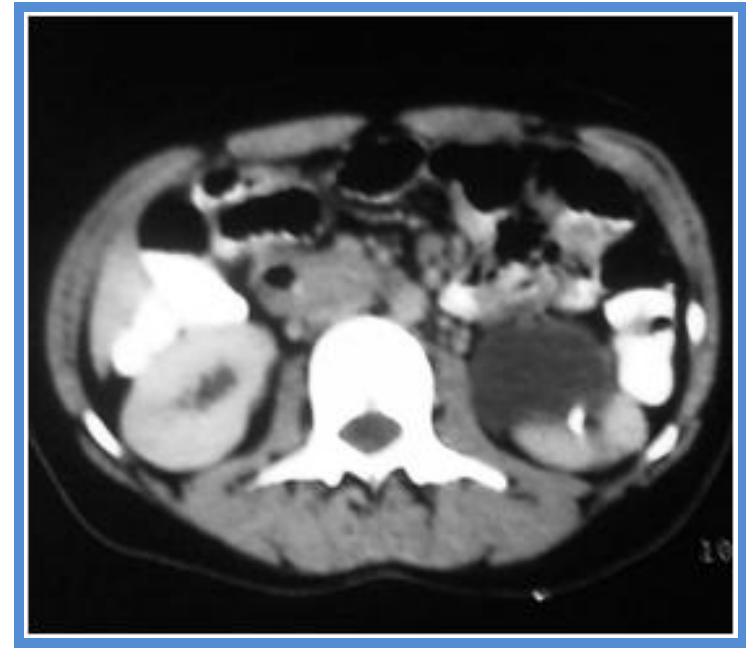

2 (b) Axial CT Scan at upper level showing a small well defined calcified calculus impacted at the neck of the cystic lesion.
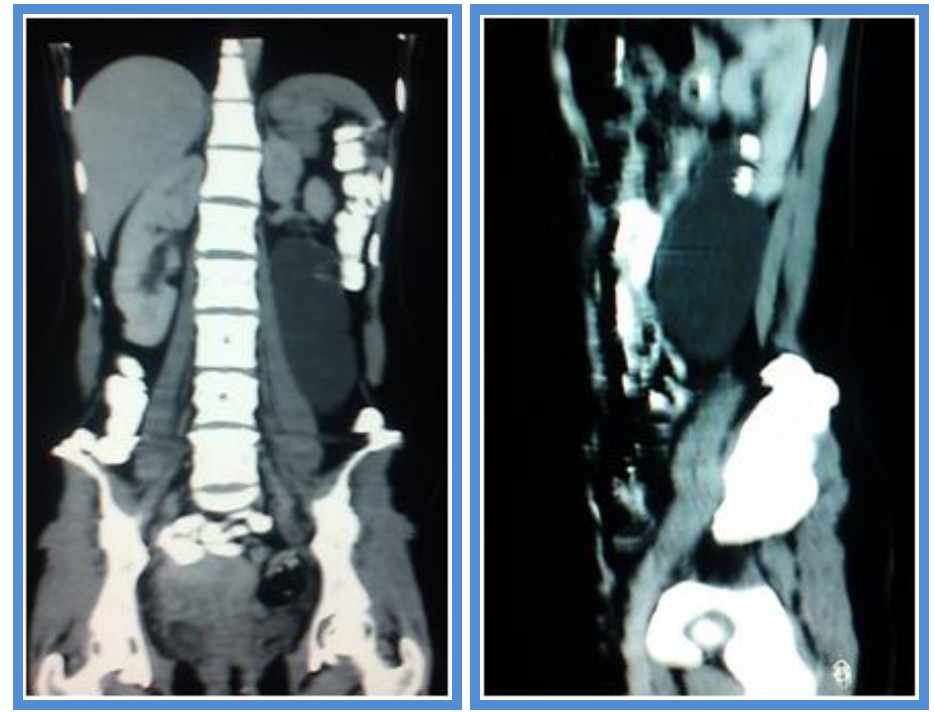

Figure. 3(a) Coronal CT Reformat showing a large oblong shaped cystic lesion in relation to the sinus of left kidney. No septation or internal solid component could be visualized 3(b) Sagittal CT Reformat showing an oblong cystic mass with about 7-14HU.Two calcified calculi could be visualized obstructing its neck. 


\section{CASE REPORT}

Patient underwent surgery and nephrostomy showed a large oblong mass in relation to renal sinus of left kidney. Fluid was aspirated from this lesion during surgical intervention which was clear, pale in color and was slightly turbid on opening this cystic lesion due to milk of calcium [Figure.4].

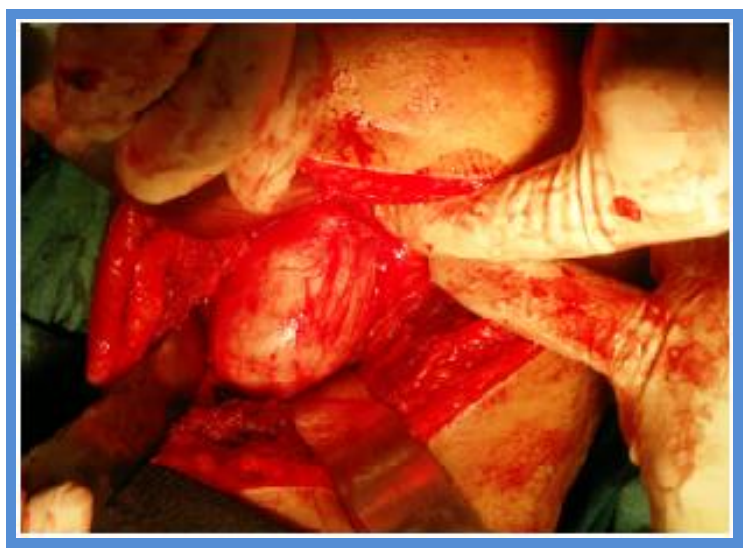

Figure. 4(a) Per-operative image showing a well defined oblong mass in relation to left kidney

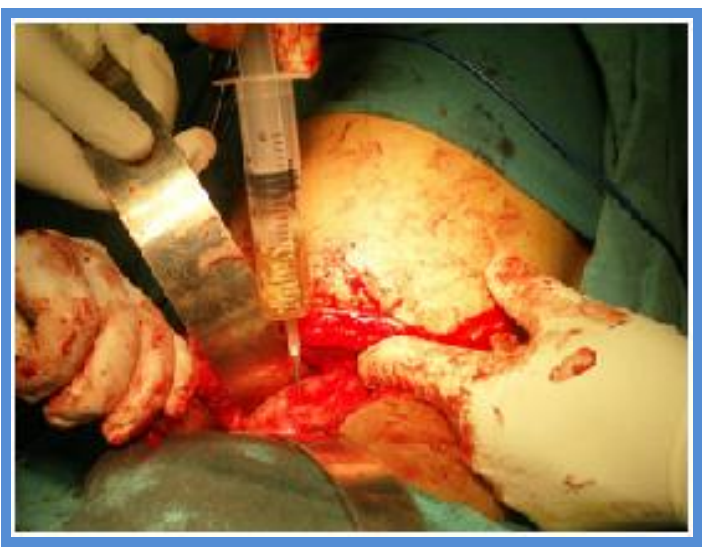

(b) Aspirate from this cyst shows clear fluid suggested of urine collection, subsequent aspirate showed slightly turbid fluid due to milk of calcium.

INTRODUCTION: Calyceal diverticula are usually diagnosed incidentally but may be symptomatic with pain due to recurrent urinary tract infection or stone formation within the diverticulum as a result of urinary stasis within the diverticulum. Other common presenting features include ipsilateral flank pain and haematuria $[4,5]$.

The term "calyceal diverticulum" was first suggested by Prather in 1941[6] and a number of etiologies have been described in the literature since then. The most widely held hypothesis is that their development is likely to be congenital in origin, resulting from failure of regression of the third or fourth divisions of the ureteric buds of the Wolffian duct [1,2]. Diverticula can rarely be acquired as a result of infection or passage of a small stone [7]. The formation of calculi or milk of calcium within a calyceal diverticulum occur secondary to a combination of urinary stasis and recurrent infection within the diverticulum.

Plain abdominal radiography is often the first radiological investigation performed in patients presenting with renal angle or flank pain suggestive of underlying renal stone disease. Plain radiography has a high sensitivity in the detection of renal tract calculi; however, this approach can be limited by overlying bowel gas. Up to $90 \%$ of renal calculi are radiopaque on plain radiographs [8].

On IVU, most calyceal diverticula will opacity owing to the connection with the collecting system. This occurs later in the examination, since the diverticulum is filled in a retrograde fashion from its connecting calyx or pelvis [9]. However, when the neck of a PCD is obstructed, the diverticulum will not opacify and it is impossible to distinguish between a renal cyst and an obstructed calyceal diverticulum. 
Abdominal ultrasound is often performed for various non-specific abdominal symptoms and is usually the first imaging modality to diagnose a PCD. The diagnosis becomes evident on ultrasound in the presence of mobile echogenic material in these cystic lesions. Awareness of the ultrasound appearance of PCD is important to reassure the clinician of its benignity and to obviate the need for other imaging studies.

Ultrasound examination suggests the diagnosis of PCD and it has a variable appearance the diverticulum may appear as a cyst-like lesion, indistinguishable from a simple cyst [3].Recognition of mobile echogenic material within such a cyst-like structure is considered characteristic of milk of calcium $[10,11]$. A cyst-like mass with milk of calcium is presumed to be a PCD [8].

Non-Contrast CT shows an uncomplicated, regular, fluid-filled space possibly with a thick outer wall, which may contain high attenuation mobile debris due to milk of calcium. Following contrast administration, layering of contrast in the dependant position is noted. The patency of the diverticulum is demonstrated by the gradual opacification on delayed scans [2]. Pyelocalyceal diverticulum may fail to opacify at IVU or CT if infection or scarring obstructs its infundibulum [12].coronal and sagittal reformatted images provide valuable anatomical information and delineate the location of the calyceal diverticulum and its relationship to the collecting system to much better effect.

Infection, hemorrhage or transitional cell carcinoma arising from its uroepithelial lining are the known complications of a pyelocalyceal diverticulum. Sealing off of the communication due to infection also has been reported to result in sealed-off abscess or cyst and rarely, xanthogranulomatous pyelonephritis [12].

Calyceal Diverticulum is usually treated by surgical intervention to marsupalise the cavity or by partial nephrectomy, along with appropriate treatment of associated calculus and other coexistent complications [13].

CONCLUSION: In conclusion, patients having renal cysts with posterior wall calcification near the renal sinus on imaging especially sonography. If USG is equivocal, supine and prone CT sections may reveal the mobile nature of the calcification and make the diagnosis of a calyceal diverticulum with calculus rather than a complicated cyst.

\section{REFERENCES:}

1. Wulfsohn MA. Pyelocaliceal diverticula. J Urol 1980; 123:1-8.

2. Jacobs RP, Kane RA. Sonographic appearance of calculi in renal calyceal diverticula. J Clin Ultrasound 1984; 12:289-91.

3. Patriquin H, Lafortune M, Filiatrault D. Urinary milk of calcium in children and adults: use of gravity-dependent sonography. AJR 1985; 144:407-13.

4. Middleton AW, Pfister RC. Stone-containing pyelocaliceal diverticulum: embryogenic, anatomic, radiologic and clinical characteristics. J Urol 1974; 111:2-6.

5. Healey T, Way BG, Grundy WR. Milk of calcium in calycine diverticula. BJR 1980; 53:845-52.

6. Prather G C. Calyceal diverticulum. J Urol 1941; 45:55.

7. Siegel MJ, McAlister WH. Calyceal diverticula in children: unusual features and complications. Radiology 1979; 131:79-82. 
8. Kabala J, Roobottom C. The kidneys and ureters. In: Sutton D, editor. Textbook of radiology and imaging, 7th Edition. London: Churchill Livingston, 2003; 2:965.

9. Middleton AW Jr, P Fister RC. Stone-containing pyelocaliceal diverticulum: embryogenic, anatomic, radiologic and clinical characteristics. J Urol 1974; 111:2-6.

10. Patriquin H, Lafortune M, Filiatrault D. Urinary milk of calcium in children and adults: use of gravity-dependent sonography. AJR 1985; 144:407-13.

11. Widder DJ, Newhouse JH. The sonographic appearance of milk of calcium in renal caliceal diverticula. JClin Ultrasound 1982; 10:448-50.

12. Davidson AJ, Hartman DS, Choyke PL, Wagner BJ. Davidson's Radiology of the Kidney and Genitourinary Tract. 3rd ed. Philadelphia: W.B. Saunders Company, 1999: 416-421.

13. H Stunell, G Mcneill, RF Browne, R Grainger, WC Torreggiani. The imaging appearances of calyceal diverticula complicated by urolithiasis. BJR 2010; 83:888-94.

\section{AUTHORS:}

1. Arvinder Singh

2. Gian S. Shergill

3. Harbhajan Kaur

4. Manjeet Kaur

\section{PARTICULARS OF CONTRIBUTORS:}

1. Associate Professor, Department of Radiodiagnosis, G.M.C. Amritsar.

2. Consultant Radiologist, Department of Radiodiagnosis, Inder Scan Centre, Amritsar.

3. Professor, Gynae \& Obs, G.M.C., Amritsar.
4. Associate Professor, Department of Physiology, S.G.R.D., Amritsar.

\section{NAME ADDRESS EMAIL ID OF THE CORRESPONDING AUTHOR:}

Dr. Arvinder Singh,

316-A Moon Avenue, Street No. 1,

Majitha Road, Amritsar, Punjab, India.

Email-arvinderdr@rediffmail.com

Date of Submission: 20/08/2013.

Date of Peer Review: 22/08/2013.

Date of Acceptance: 29/08/2013.

Date of Publishing: 10/09/2013 